\title{
RESENHA / BOOK REVIEW
}

Thornley, Davinia. Cinema, Cross-Cultural Collaboration, and Criticism: Filming on an Uneven Field. Basingstoke: Palgrave Macmillan, 2014.

By Ketlyn Mara Rosa*

Universidade Federal de Santa Catarina, Florianópolis, SC, Brazil

The issue of cinematic collaborations across cultures is discussed by Davinia Thornley in her book through a close reading approach that encompasses the textual layers of films, but also the production levels in which the collaboration among cultures stands out as a source of conflict and learning. Her focus on indigenous cinema locates the analysis on examples from the Commonwealth countries of Canada, Australia, and Aotearoa New Zealand, exploring fictional films and documentaries produced in a collaborative process by both indigenous and nonindigenous crew and cast. Such partnership becomes a focal point in her discussion of how cinematic collaborations can help open up spaces of dialogue and self-expression for the indigenous groups that start in the production phase and must be carefully acknowledged in the criticism of such films. Thornley sensibly calls attention to the singularity of indigenous films and how these works speak from very specific places and cultures, extending her criticism and analysis not only to the role of nonindigenous members in indigenous films, but also exploring the indigenous participation in the artistic creations. Collaboration becomes a keyword for the production of cross-cultural films that find themselves in the crossroads between the requirements of an industry inserted in a commercial context and the needs of recovering and transmitting the visual history of indigenous peoples.

One of the main subjects discussed in her book is the afterlife of indigenous films and their contribution to society through a process of continuing conversation among the artistic creators and the audience, whether they come from an indigenous background or not. Although Thornley seems to underline the positive outcomes of such interaction in terms of a greater awareness of indigenous culture and an effort to foster indigenous self-expression, she recognizes the shortcomings of crosscultural undertakings in the form of inequalities experienced in a power-sharing

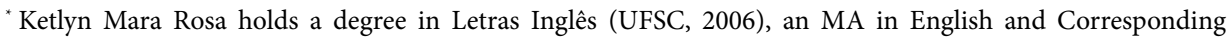
Literature (UFSC, 2015), and is currently a doctoral candidate at Programa de Pós-Graduação de Inglês at Universidade Federal de Santa Catarina. Her research looks into the issues of landscape and technology in representations of contemporary war in cinema, specifically in films that take place during the Afghanistan and Iraq wars. In recent years, Ketlyn has researched on portrayals of combat and violence in war films and miniseries. E-mail: ketlynrosa@yahoo.com.br. 
environment. She comments that when nonindigenous and indigenous "groups with such different (and often directly conflicting) histories, agendas, and worldviews attempt to work together," there is always the risk of creating an unbalanced production atmosphere that can have an impact on the film's artistic choices (3). Thornley chooses to analyze cross-cultural films in a wider cultural, financial, and political context in order to highlight that such problematic interactions are part of a complex structure that must be acknowledged by film critics. The conflicts, arrangements, and partnerships that spring from the production of indigenous films are nuances that, if taken into consideration, promote a critical understanding of cross-cultural artistic collaborations.

In the introductory chapter, Thornley expands on her attempt to foreground a film criticism that does not solely focus on the cultural inaccuracies concerning indigenous cinema, such as stereotypical and superficial portrayals, but also brings to the surface the collaborative aspects of production. This fresh perspective embraces representations as ongoing processes that focus on productive interactions between the nonindigenous and indigenous crew and cast, expanding the cultural and social results achieved through an active relationship with the audience. The book concentrates on collaborative aspects of films that "have created change on industrial, as well as discursive and ideological, levels" (4). Instead of disregarding cross-cultural collaborative efforts based on their seemingly lack of cultural depth in the storyline, Thornley emphasizes that the multiple layers that constitute a film, such as an ideologically active production environment, thematic interests, aesthetic concerns, and audience reception, must be acknowledged and appreciated so that representations of indigenous visual heritage retain a place in the next generation's imaginary while also promoting further creative partnerships.

Thornley's careful use of the term "Fourth Cinema" throughout the book demonstrates her focus on cinema's role to challenge sovereign perspectives and promote political autonomy for the indigenous peoples while avoiding the binary restrictions that the term entails. Fourth Cinema was coined by Barry Barclay and "suggests a separate, but not lower, designation (as the numerical order might suggest) for films made by and addressing indigenous peoples and their concerns" (5). Thornley points out the binary constraints of such expression, namely "white versus Aboriginal filmmaker, stereotypical versus authentic representation, dominant versus marginal cinema" (8), but chooses to break free from these dualisms so collaboration becomes an organic and positive possibility. Fourth Cinema is not seen by the author as a term that stresses separation and animosity, but as a source of projects that make use of artistic endeavors to bring cultural, political, and economic improvements to indigenous communities. Thornley shows an awareness of the difficulties in dealing with knowledge gaps from the participants of the projects regarding the indigenous cultural heritage, but she affirms that dialogue and an emphasis on cross-cultural communication must be encouraged, so that the input from the indigenous peoples can gradually occupy a more prominent place in every step of the artistic creation. 
The remaining book chapters offer a variety of filmic study cases that combine textual and non-textual analysis, enhancing the role of collaborative criticism and its vital connection to the contextual factors surrounding the artistic works. The second chapter is centered on the film Before Tomorrow (2008), a collaborative project by a First Nations director, Madeline PiujuqIvalu, and a Quebecois director, MarieHélène Cousineau. The storyline of the film deals with the struggle for survival of an Inuit woman and her grandson amidst the harsh weather of the Artic North and the threat of diseases. Thornley provides the context in which this movie is produced by highlighting the collaborative partnership between Ivalu and Cousineau, and how their productive relationship blossomed into concrete developments in terms of self-expression in the indigenous community. The bleak destiny of the characters in the film, who ultimately succumb to the weather and isolation, can be understood as a somber tale about the devastation of indigenous culture and people. This is undoubtedly a significant critical asset of the film, but Thornley's unique analysis foregrounds the stark contrast between such a desolate circumstance and the constructive environment of production and reception. She observes the importance of the "disjunction highlighted between the textual 'deaths' on screen and the political, social, and cultural energy produced in the creation of this film" (29). Before Tomorrow does not only textually address significant issues related to the identity and heritage of indigenous peoples, but also enters the local context by promoting a dialogue and a close relationship between nonindigenous and indigenous crew and cast, creating a cross-cultural collaborative project that focuses on the exchange of information and practical reverberations concerning self-expression in the communities.

Thornley expands her vision of a collaborative production that allows constructive effects to surface in a local and global context by looking into the on-screen and offscreen impact of nonindigenous participation in the film. While in the storyline diseases are brought to the indigenous communities by outside forces, in an offscreen context the elements introduced by Cousineau and her team, that is, filmmaking abilities and equipment, "enable Inuit communities to relearn their philosophy, to gain jobs, to transmit their traditions, and-in so doing-to flourish" (31). The collaborative effort between Cousineau and Ivalu during production was extended to community screenings and further editing of the film. After the shooting was over, there was the initiative to offer workshops that introduced the community to filmmaking, an attempt to teach locals how to use artistic tools through which they could express themselves. Thornley continues her analysis by focusing on the boundless afterlife of the film through the DVD extra features. Cast and crew interviews, outtakes, and documentaries constitute a new narrative that goes beyond the death of the characters on the screen and depicts a community that is engaged to represent their own history in a collaborative and active manner.

The third chapter engages with the historical context and production complexities during the making of the documentary Lousy Little Sixpence (1983), directed by New Zealander Alec Morgan and co-produced by Gerry Bostock from the Australian 
Bundjalung nation. The major theme of the documentary is the taking of Aboriginal children from their families and later captivity into hard labor, a subject not discussed for a long time in Australian society. Thornley points out that the collaboration between nonindigenous and indigenous artists in the making of the film is another example of a partnership, in this case between Australian and indigenous communities, that "continue[s] to find and create images and film in the process of recovering and making [indigenous peoples'] own visual history" (52). Morgan's insertion into the daily lives of the local communities started with an earlier project involving puppets and narratives that approached themes of cross-cultural prejudice. Thornley attentively observes that the process of building a close relationship with the indigenous community was vital for Morgan's next project, the documentary Lousy Little Sixpence. Through open dialogue with local members, Morgan became aware of the fractured state of Aboriginal history and how some histories were concealed from general knowledge due to an overwhelming feeling of suppression and shame. As the documentary focuses on the "lost histories," the author highlights, marginal voices are brought to the forefront and made accessible to the public (57).

While Thornley brings together the production circumstances of the documentary and the personal heritages of both director and co-producer, she foregrounds one of the most important effects of a cross-cultural collaborative endeavor: the creation of a space for self-expression. The documentary combines archival footage from newsreels and propaganda with intimate testimonies of indigenous members of the community that were somehow affected by this traumatic episode. Thornley emphasizes that the use of archival footage exposes "the remnants of dominant ideologies in order to show current viewers how such images and ideas allowed wholesale cultural genocide not only to be accepted, but to be institutionally condoned" (59). The interviews with the community members function as an attempt to bring to the surface the issue that the Aboriginal Australians have had their voices silenced throughout mainstream history. The key privilege of self-expression was denied amidst the suppression of a shameful past. Thornley exposes this historical background and places the documentary at the center of a major reception discussion in which audience reactions to the testimonies are of surprise and shock due to the retelling of horrific life conditions.

Chapter four continues the book's journey into case studies by dealing with a significant facet of indigenous portrayals: mainstream representations in film. By tackling four films, The Tattooist (Peter Burger 2007), Whale Rider (Niki Caro 2003), No. 2 (Toa Fraser 2005), and Apron Strings (Sima Urale 2008), Thornley expands on the shortcomings of cross-cultural productions as well as their productive aspects. She critically observes that some of these films, especially in the case of The Tattooist, the storyline suffers from an excess of "essentialism, stereotyping, [and] cultural shorthand" (75) that strays away from a constructive dialogue and portrayal of indigenous culture. All four films "commercialize indigeneity and difference, in such a way that vital cultural beliefs are modified or even discarded in the long march to feature film production" (76). The practice of simplifying one-of-a-kind traditions in 
indigenous culture, in order to render such heritage intelligible for the nonindigenous viewers, inhibits the process of discovery and interactive understanding that Thornley believes is crucial to the crew, cast, and audience in contact with a cross-cultural artistic work.

Although the four films discussed in this chapter present several problematic issues of exoticization and interpretation of indigenous culture, Thornley foregrounds their role in the greater social context of indigenous self-expression. She claims that they can be seen as "concerted attempts to cross cultural boundaries and to mediate historical ruptures" (78). Whale Rider focuses on complex questions of race and social accountability while creating a platform for the indigenous community to portray their issues and history. During the production of the film, scripts were given to the local tribes and subtribes in order to garner their input in a collaborative process. Thornley highlights the similarity between No. 2 and Apron Strings since their major theme can be understood as the struggle of indigenous groups to establish themselves in New Zealand. Her cross-cultural collaboration angle of analysis establishes No. 2 as a productive example in which indigenous members are given the opportunity to express themselves on-screen and offscreen, and filmmaking skills become a collective property of the communities. Thornley brings Apron Strings to the forefront by emphasizing the film's focus on representing the encounters of different ethnic groups. By seeing themselves on screen, spaces of self-expression are further promoted, leading to a greater dialogue and learning of distinct cultures. When addressing cross-cultural films in general, the author states that "it is essential to recognize that cinematic exploration is always political, simply because ways of making meaning are never neutral but rather exist in relation to class issues and historical contexts" (101). Even if the films from this chapter are produced in a mainstream context, the analysis of textual and non-textual characteristics offers a chance of looking further into the ways these artistic representations have an impact on a local and global scale.

The concluding chapter reiterates the need for an immersive criticism of crosscultural collaborations in cinema in which the contextual elements of production are fundamental for a broader understanding of the interactions that contribute to the final artistic work seen by the audience. Thornley acknowledges that collaborative criticism "provides a gateway for both indigenous and nonindigenous viewers and practitioners to enter into respectful conversations about these films and their worldviews" (110-111). Interaction, dialogue, engagement, and immersion are keywords highlighted by the author when discussing the aspects that a critic must have in mind during an analysis of a cross-cultural artistic work. Another aspect emphasized by Thornley is the regeneration that occurs in the relationship between film and audience. It can be perceived in the form of an increase in the pursuit of further information about indigenous groups, the changes that can possibly take place in the viewer when faced with a different representation from the traditional mainstream history as well as the public articulation of a desire to see similar projects. 
The author attentively restates that the afterlife of each cinematic project should also be taken into consideration when critically analyzing a film. She observes that "collaborative criticism continues [a political] conversation after the event is over, outside of the theater, into the academy and beyond, reaching out into the larger world" (115). Thornley's fresh contextual perspective on cinematic analysis brings a group of vivid and theoretically solid case studies of indigenous films that support the focus on partnership and self-expression issues. Her efforts to delve into productive cross-cultural collaborations characterize them as ongoing journeys in which future improvements are achieved by the pursuit of such relationships. This viewpoint promoted in the book brings a valuable and constructive tone to cinematic criticism that highlights the coming together of different cultures in the creation of artistic projects.

\section{References}

Thornley, Davinia. Cinema, Cross-Cultural Collaboration, and Criticism: Filming on an Uneven Field. Basingstoke: Palgrave Macmillan, 2014.

Recebido em: 19/10/2017

Aceito em: 26/03/2018 